\title{
Extended-Spectrum Beta-Lactamase and Carbapenemase Producing Enterobacteriaceae among Patients with Gastrointestinal Complaints in North West Ethiopia
}

\section{Minichil Worku}

University of Gondar College of Medicine and Health Sciences

Michael Getie

University of Gondar College of Medicine and Health Sciences

\section{Feleke Moges}

University of Gondar College of Medicine and Health Sciences

Alem Getaneh ( $\square$ alemgetaneh2@gmail.com )

University of Gondar College of Medicine and Health Sciences, school of biomedical and laboratory sciences https://orcid.org/0000-0003-1608-6737

\section{Research}

Keywords: Enterobacteriaceae, MDR, ESBL, CRE, Gondar

Posted Date: December 26th, 2019

DOl: https://doi.org/10.21203/rs.2.19646/v1

License: (9) (i) This work is licensed under a Creative Commons Attribution 4.0 International License. Read Full License 


\section{Abstract}

\section{Background}

Antimicrobial resistance is an increasing threat to health systems which leads to treatment failure, high treatment costs and increased mortality. Infections due to extended spectrum beta-lactamase (ESBL) and carbapenemase producing Enterobacteriaceae(CPE) impose a major global issues, because they are usually resistance to multiple antimicrobial agents. Data on the fecal ESBL producing Enterobacteriaceae (ESBL-PE) and CPE in developing countries including Ethiopia is limited mainly due to resource constraints. Thus, the aim of this study was to determine the prevalence of MDR, ESBL and CPE among patients with gastrointestinal complaints at the University of Gondar Comprehensive Specialized Hospital, Gondar; Northwest Ethiopia.

Materials and Methods

A Hospital based cross-sectional study was conducted among 384 patients with gastrointestinal complaints from January - April 2019 at the University of Gondar Comprehensive Specialized Hospital. A stool sample was aseptically collected and inoculated on MacConkey agar plate. After getting pure colonies, biochemical testing and antimicrobial susceptibility testing were done following standard microbiological techniques. ESBL production was screened by using ceftazidime and cefotaxime and confirmed using a combined disk diffusion test based on CLSI 2019 guidline. Carbapenemases were screened by meropenem disc and confirmed by modified carbapenem inactivation method. Data was checked, cleaned and entered using Epi-Info version 7.1 and transferred to SPSS version 20 for analysis. P-value $<0.05$ at $95 \% \mathrm{Cl}$ was considered as statistically significant.

Result

Out of the 384 study participants, 404 Enterobacteriaceae were isolated. Among these, 196 (48.5\%) were MDR. The overall prevalence of fecal ESBL and CPE were 66(16.3\%) and 4(1\%) respectively. Of the total ESBL-PE, E.coli $41 / 66(62.1 \%)$ and K.pneumoniae 18/66(27.3\%) were the most predominant isolates.

Conclusion

Finding high rate of MDR Enterobacteriaceae,ESBL-PE and CPE require strict infection control measures and careful selection of empirical therapy in the study area. Therefore, active surveillance with large sample size and better infection prevention and control is needed.

\section{Background}

Enterobacteriaceae are a group of Gram-negative, rod-shaped facultative anaerobe and their natural host is the human as well as animal intestine $(1,2)$. The human gastrointestinal tract is a reservoir for pathogens causing infections including urinary tract infections, nosocomial infections, skin and soft tissue infections. Bacterial translocation is the invasion of indigenous intestinal bacteria through the gut mucosa to normal sterile tissues and the internal organs $(3,4)$. Colonization of the gastrointestinal tract plays a key role in the epidemiology and clinical significance of extended spectrum beta lactamase (ESBL) and carbapenamase producing bacteria (5).

Extended spectrum beta lactamase-producing Enterobacteriaceae (ESBL-PE) have been reported worldwide since the early 1980s (6). In the past decade, there has been an alarming increase in antibiotic-resistant Enterobacteriaceae 
producing ESBL due to overuse of broad-spectrum cephalosporins (7). Fecal ESBL-PE in the community was first reported in Spain and Poland in 2001 and 2002, respectively (8).

Extended spectrum beta lactamase producing Enterobacteriaceae have worldwide distributions with varying degree of prevalence in the community as well as hospitals $(9,10)$. Infections due to ESBL-PE and carbapenemaseproducing Enterobacteriaceae (CPE) represent a major global health threat because they are usually resistant to multiple antimicrobial agents and lack of carbapenem drugs $(11,12)$. Although antimicrobial resistance is a global problem, the impact is higher in Sub-Saharan Africa due to limited available resources for healthcare infrastructure and wide irrational use of antimicrobial agents. From those who take antibiotics, more than one-third do not get prescriptions from a doctor and about a quarter obtain antibiotics from an informal dispenser $(13,14)$. Currently, infections due to ESBL-PE are concerning for many reasons including increased hospital costs, length of stay, treatment failure and mortality rates (15).

Carbapenemase producing Enterobacteriaceae are difficult to treat because of high levels of resistance to many antibiotics that break down all $\beta$-lactam agents including carbapenems and make it ineffective (16). The rise of $ß$ lactamase producing Gram-negative multidrug-resistant (MDR) organisms such as ESBL or carbapenemaseproducing bacteria is the major particular concern (17-19).

The human gastrointestinal tract contains abandon normal flora and may act as a reservoir for other pathogens and these organisms that may contain the resistance gene may translocate through the gut mucosa to normal sterile tissues and the internal organs. As a result it may increase the resistance pattern in other sterile body site. However, data on the fecal ESBL and CPE is limited in developing countries especially in Ethiopia, particularly Gondar. Having the information on resistance pattern of normal commensals of human gastrointestinal tract are very important to encourage the prevention and control measures of the emergence of antimicrobial resistant strains.So this research intended to determine the magnitude of the intestinal ESBL and CPE at the University of Gondar Comprehensive Specialized Hospital.

\section{Materials And Methods}

\section{Study design, area and period}

A Hospital-based cross-sectional study was conducted at the University of Gondar Comprehensive specialized Hospital in Gondar town; Northwest Ethiopia, from January-April 2019. The town is located $737 \mathrm{~km}$ far from Addis Ababa, the capital city of Ethiopia and $180 \mathrm{~km}$ far from Bahir Dar, the regional capital. According to the central and statistical agency of Ethiopia report in 2015, the town has twelve sub city, twenty-two urban and eleven rural kebeles with a total projected population of 323,900 . There are 8 health centers, 21 private clinics and one primary hospital in the town. The hospital provides health care service for more than 5 million people living in North, South, West Gondar Zones, as well as urban and rural kebeles surrounding the town.

\section{Sample size and sampling technique}

The sample size was determined using the single population proportion formula. By taking the prevalence of ESBLs and CPE infection that was conducted at Tikur Ambesa Specialized Hospital which showed $0.52(13,20)$, a total of 384 study participants were enrolled by using convenient sampling technique. 


\section{Laboratory Methods}

Specimen collection and processing: The study participants were instructed to collect approximately 2 gram of diarrheal stool in to a clean, leak-proof container. The specimen of the study participants were collected at the University of Gondar Comprehensive specialized Hospital laboratory. Each stool sample was immediately transported to school of Bio medical and Laboratory Sciences, Medical Microbiology laboratory section using CaryBlair transport media. Following an aseptic technique, a loop full of diarrhoeal sample was inoculated onto MacConkey agar (oxoid, Code: CM0115) and incubated aerobically at $37^{\circ} \mathrm{C}$ for $16-24$ hours.

\section{Identification}

Preliminary identification: Preliminary identification of bacteria was based on their colony characteristics of the organisms.

Biochemical tests: were performed on isolated colonies for identification of Enterobacteriaceae based on their biochemical reaction. Biochemical tests includes triple sugar iron agar, indole test, citrate utilization test, urease production test, lysine decarboxylase test and motility test (21).

Drug susceptibility testing: Modified Kirby-Bauer disk diffusion technique using Muller Hinton agar (MHA) (Oxoid, UK) was used for antimicrobial susceptibility testing. Bacterial s uspension of three to five isolated colonies was done using $0.85 \%$ normal saline and the turbidity was adjusted at $0.5 \%$ MacFarland standard. Using sterile cotton applicator stick, the suspension had been inoculated on MHA and left at room temperature for 3-5 minutes until it becomes dry. Then, diifferent antibiotic discs including ceftazidime $(30 \mu \mathrm{g})$ and cefotaxime $(30 \mu \mathrm{g})$ were applied on inoculated MHA and incubated for $24 \mathrm{hr}$ at $37^{\circ} \mathrm{C}$. Ceftazidime $(30 \mu \mathrm{g})$ and cefotaxime $(30 \mu \mathrm{g})$ discs were used for presumptive identification of ESBL production. The zones of inhibition was measured by a ruler and the results were interpreted as susceptible, intermediate and resistant using CLSI 2019 performance Standards for antimicrobial susceptibility testing interpretation table. Zone of inhibition $\leq 22 \mathrm{~mm}$ for ceftazidime and $\leq 27 \mathrm{~mm}$ for cefotaxime, was considered as potential ESBL producers (22).

\section{Laboratory test for detection of ESBL and CPE}

Confirmatory test for ESBL producer: The potential ESBL-PE was confirmed by combined disk method.Colony suspension of suspected ESBL-PE was inoculated on to MHA, then Ceftazidime $(30 \mu \mathrm{g})$ and Ceftazidime-Clavunalic acid $(30 / 10 \mu \mathrm{g})$, Cefotaxime $(30 \mu \mathrm{g})$ and Cefotaxime-Clavunalic acid $(30 / 10 \mu \mathrm{g})$ disks were placed at $20 \mathrm{~mm}$ distance apart. If a $\geq 5 \mathrm{~mm}$ increase in a zone diameter for either antimicrobial agent tested in combination with clavulanate vs the zone diameter of the agent when tested alone, it was confirmed as ESBL-PE (22).

Screening test for CPE: Carbapenemase producing Enterobacteriaceae was screened by using Meropenem disks.Colony suspension of isolated bacteria was inoculated on to MHA, then Meropenem (10 $\mu \mathrm{g})$ disks were placed and incubated at $37^{\circ} \mathrm{C}$ for $24 \mathrm{hrs}$. If the zone of inhibition is $\leq 19 \mathrm{~mm}$, it was considered as a potential CPE (22).

Confirmatory test for CPE: The suspected CPE is confirmed by Modified carbapenem inactivation method (mCIM). The isolated bacterial colony which was suspected for CPE was diluted with $2 \mathrm{ml}$ of trypticase soya broth and meropenem $(10 \mu \mathrm{g})$ disk was immersed in the suspension; then incubate for 4 hours. A standard strain of meropenem susceptible E.coli ATCC 25922 was suspended in $0.85 \%$ normal saline and compared with MacFarland 
standard (1:10 dilution) then inoculated the whole plate of MHA. After 4 hrs incubation, meropenem disk was removed from the test tube and placed on the MHA plate which was inoculated by E.coli ATCC 25922 meropenem sensitive strain and incubated at $37^{\circ} \mathrm{C}$ for $18-24$ hours. After incubation, if the zone of inhibition diameter between 6-15 $\mathrm{mm}$ and $16-18 \mathrm{~mm}$ with pinpoint colony, it was considered as carbapenem resistance Enterobacteriaceae (22).

\section{Operational definitions}

ESBL producers are bacteria that can produce the enzymes that confer resistance to most beta-lactam antibiotics (23).

MDR defined as resistance to three or more different classes of antibiotics (13).

Carbapenemases are beta-lactamase enzymes that inactivate almost all hydrolyzable beta-lactam antibiotics including the carbapenems (23).

Gastrointestinal tract complain is a discomfort in gastrointstinal tract with abdominal cramp, diarrhea, vomiting and distension of the abdomen (24).

\section{Labolatory Quality control}

All Medias were prepared according to the manufacturer's instruction and following standard operational procedure. All materials, equipment, and procedures was adequately controlled based on pre-analytical, analytical and postanalytical stages of quality assurance that were incorporated in standard operating procedures at the School of Biomedical and Labolatory Sciences of Bio-Medical complex of Medical Microbiology section. Culture media was checked for sterility by incubating $5 \%$ batch of the media at $37^{\circ} \mathrm{C}$ for 24 hours and performance test was checked by inoculating known control strains of Escherichia coli ATCC 25922 and K. pneumoniae ATCC $B 700603$ to confirm consistency of materials, methods and results. K. pneumoniae ATCC ${ }^{B A A} 1705$ and ATCC ${ }^{B A A} 1706$ were used as a positive and negative quality control respectively for carbapenemase production.

\section{Data analysis and interpretation}

Data were collected, coded and entered in to EPI-Info version-7 to check completeness and clearance then transferred to SPSS version 20 for analysis. The characteristics of the study population were summarized using frequencies, percentages, mean and standard deviation and data was presented using tables.

\section{Results}

\section{Socio-demographic characteristics of the study participants}

Out of 384 study participants, 200(52.1\%) were males while the remaining were females. The mean age of the study subjects were $30.76 \pm$ SD 16.93. The highest frequency age group of the study participants were 16-30 years old $170(44.1 \%)$ and most of the study participants were urban residents $225(58.6 \%)$. Majority $310(80.7 \%)$ of the study participants were from outpatient department while the remaining were from inpatients (Table 1). 
Table 1: Socio-demographic characteristics of patients with gastrointestinal complaints at the University of Gondar Comprehensive Specialized Hospital, Northwest Ethiopia, January- April, 2019.

\begin{tabular}{|c|c|c|}
\hline \multicolumn{2}{|c|}{ Demographic characteristics } & \multirow{2}{*}{$\begin{array}{c}\text { Number (\%) } \\
200(52.1)\end{array}$} \\
\hline Gender & Male & \\
\hline \multirow{7}{*}{$\begin{array}{l}\text { Age category } \\
\text { (year) }\end{array}$} & Female & $184(47.9)$ \\
\hline & $\leq 5$ & $28(7.3)$ \\
\hline & $6-15$ & $32(8.3)$ \\
\hline & $16-30$ & $170(44.3)$ \\
\hline & $31-45$ & $77(20.1)$ \\
\hline & $46-60$ & $52(13.5)$ \\
\hline & $>61$ & $25(6.5)$ \\
\hline \multirow[t]{2}{*}{ Residence } & Rural & $159(41.4)$ \\
\hline & Urban & $225(58.6)$ \\
\hline \multirow{6}{*}{ Occupation } & Farmer & 65 (16.9) \\
\hline & Civil servant/employee & $94(24.5)$ \\
\hline & Private & $27(7.0)$ \\
\hline & House wife & $48(12.5)$ \\
\hline & Student & $100(26.0)$ \\
\hline & Other & $50(13.0)$ \\
\hline \multirow[t]{5}{*}{ Educational level } & Illiterate & $89(23.1)$ \\
\hline & Primary school & $102(26.6)$ \\
\hline & Secondary school & $46(12.0)$ \\
\hline & Higher education & $119(31)$ \\
\hline & N/A & $28(7.3)$ \\
\hline \multirow[t]{3}{*}{ Marital status } & Married & $192(50.0)$ \\
\hline & Single & $184(47.9)$ \\
\hline & Divorced & $8(2.1)$ \\
\hline \multirow[t]{2}{*}{ Department } & Inpatient & $74(22.9 \%)$ \\
\hline & Out patient & $310(80.7 \%)$ \\
\hline
\end{tabular}

\section{Prevalence of Enterobacteriaceae}

Out of 384 study participants, 404 Enterobacteriaceae were isolated in diarrhoea stool sample. From the total isolated Enterobacteriaceae, E.coli accounts the highest 219(54\%) followed by K.pneumoniae 50(12\%), K. ozenae 15(3.7\%), Citrobacter species14(3.5\%), Shigella species 10(2.5\%), E.cloacae 7(1.7\%), Proteus species 6(1.5\%), Serratia species 6(1.5\%), E.aerogenes 1(0.2\%), S.typhi 1(0.2\%), and others Enterobacteriaceae 75(18.6\%).

\section{Multi Drug Resistant Patterns of Enterobacteriaceae}


A total of twelve antibiotics such as Ampicillin, Ampicilin/Clavunalic acid, Gentamicin, Tobramycin, Tetracycline, Ciprofloxacin, Trimethoprim-sulfamethoxazole, Cefoxitin, Cefepime, Cefexime, cefuroxime and Ceftazidime or seven classes of antibiotics were used for antimicrobial Susceptibility Patterns of Enterobacteriaceae (Table 2). Of the total 404 isolated Enterobacteriaceae, 196(48.5\%) were MDR that are resistant to three or more antibiotic classes. Among these, E.coli accounts the highest 118(60.2\%), followed by K.pneumoniae 37(18.9\%), K.ozenae 12(6.1\%), Citrobacter species 10(5.7\%), Proteus species 6(3.1\%), Serratia species 5 (2.5\%.\%) and E.cloacae 4(2.1\%) (Table 3 ).

Table 3: Prevalence of MDR-Enteobacteriaceae from Patients with Gastrointestinal Complaints at the University of Gondar Comprehensive Specialized Hospital from January - April, 2019

\begin{tabular}{llllll|}
\hline Isolates & \multicolumn{2}{l}{ Degree of resistance } & & \\
\hline & R3 & R4 & R5 & R6 & R7 \\
\hline E.coli $(\mathrm{N}=118)$ & $30(25.4 \%)$ & $34(28.8 \%)$ & $29(24.5 \%)$ & $20(16.9 \%)$ & $5(4.2 \%)$ \\
K.pneumoniae $(\mathrm{N}=37)$ & $12(32.4 \%)$ & $11(29.2 \%)$ & $9(24.3 \%)$ & $3(8.1 \%)$ & $2(5 \%)$ \\
K.ozenae $(\mathrm{N}=12)$ & $6(50 \%)$ & $3(25 \%)$ & $2(16.6 \%)$ & $1(8.3 \%)$ & --- \\
Citrobacter species $(\mathrm{N}=10)$ & $2(20 \%)$ & $7(70 \%)$ & $1(10 \%)$ & -- & - \\
Proteus Vulgariss $(\mathrm{N}=6)$ & $4(66.6 \%)$ & $1(16.7 \%)$ & $1(16.6 \%)$ & - & - \\
E.cloacae $(\mathrm{N}=4)$ & - & $2(50 \%)$ & $1(25 \%)$ & $1(25 \%)$ & - \\
Salmonella species $(\mathrm{N}=1)$ & - & $1(100 \%)$ & - & - & - \\
Shigella species $(\mathrm{N}=3)$ & $2(66.7 \%)$ & $1(33.3 \%)$ & - & - & - \\
Serratia species $(\mathrm{N}=5)$ & $3(60 \%)$ & $1(20 \%)$ & $1(20 \%)$ & - & - \\
Total $(\mathrm{N}=196)$ & $59(30.1 \%)$ & $60(30.6 \%)$ & $44(22.4 \%)$ & $25(12.7 \%)$ & $7(3.5 \%)$ \\
\hline
\end{tabular}

Note: R3, R4, R5, R6 and R7: Resistance to 3, 4, 5, 6, and 7 classes of antibiotics respectively.

\section{Prevalence of ESBL and Carbapenemase Producing Enterobacteriaceae}

Based on the CLSI standard only E. coli, K.pneumoniae, K.ozenae and Proteus vulgaris were screened using Ceftazidime $(30 \mu \mathrm{g})$ and cefotaxime $(30 \mu \mathrm{g})$ discs and tested for ESBL production. Of the total of 404 isolated Enterobacteriaceae, 106(26.3\%) were screened positive and 66/106(62.2\%) were confirmed ESBL-PE. Of these, E. coli accouns 41 (62.1\%) followed by K.pneumoniae 18(27.3\%), K.ozenae 4 (6\%) and Proteus vulgaris 3(4.5\%) (Figure 1). As per CLSI 2019 Guildline, other Enterobacteriaceae groups were excluded from ESBL detection because they have no breakpoint in the guidelines.

A total of 105 Enterobacteriaceae ( 66 were confirmed ESBL-PE and the rest 39 were other Enterobacteriaceae) were screened for carbapenemase production by using Meropenem disk. Among these, 4(6\%) such as [Citrobacter species (2), E.coli and P.vulgaris each accounts 1] were presumptive carbapenemase producer. These four presumptive CPE were confirmed by modified carbapenem inactivation method (mCIM) and all 4/4(100\%) were CPE. From the total CPE, Citrobacter species accounted 2 (50\%), E.coli 1(25\%) and P.vulgaris 1 (25\%) (Table 4).

Table 4: Distribution of ESBL and Carbapenemase producing Enterobacteriaceae from Patients with Gastrointestinal Complaints at the University of Gondar Comprehensive Specialized Hospital from January to April, 2019. 


\begin{tabular}{|c|c|c|c|c|c|c|c|c|}
\hline \multirow[t]{2}{*}{ Bacterial Isolates } & \multicolumn{2}{|c|}{$\begin{array}{l}\text { ESBL Screening } \\
\mathrm{N}(\%)\end{array}$} & \multicolumn{2}{|c|}{$\begin{array}{l}\text { Confirmed ESBL } \\
\mathrm{N}(\%)\end{array}$} & \multicolumn{2}{|c|}{$\begin{array}{l}\text { CPE Screening } \\
\mathrm{N}(\%)\end{array}$} & \multicolumn{2}{|c|}{$\begin{array}{l}\text { Confirmed CPE } \\
\mathrm{N}(\%)\end{array}$} \\
\hline & Positive & Negative & Positive & Negative & Positive & Negative & Positive & Negativ \\
\hline E.coli & $69(65 \%)$ & 150 & $41(62 \%)$ & $28(70 \%)$ & $1(25 \%)$ & $40(40 \%)$ & $1(25 \%)$ & 0 \\
\hline K.pneumoniae & $29(27 \%)$ & 21 & $18(27 \%)$ & $11(28 \%)$ & 0 & $18(18 \%)$ & 0 & 0 \\
\hline K.ozenae & $4(4 \%)$ & 11 & $4(6 \%)$ & 0 & 0 & $4(4 \%)$ & 0 & 0 \\
\hline Citrobacter & $\mathrm{N} / \mathrm{T}$ & $\mathrm{N} / \mathrm{T}$ & $\mathrm{N} / \mathrm{T}$ & $\mathrm{N} / \mathrm{T}$ & $2(50 \%)$ & $12(12 \%)$ & $2(50 \%)$ & 0 \\
\hline \multicolumn{9}{|l|}{ species } \\
\hline Proteus Vulgariss & $4(4 \%)$ & 2 & $3(5 \%)$ & $1(3 \%)$ & $1(25 \%)$ & $2(2 \%)$ & $1(25 \%)$ & 0 \\
\hline E.cloacae & $\mathrm{N} / \mathrm{T}$ & $\mathrm{N} / \mathrm{T}$ & $\mathrm{N} / \mathrm{T}$ & $\mathrm{N} / \mathrm{T}$ & 0 & $7(7 \%)$ & 0 & 0 \\
\hline S. typhi & $\mathrm{N} / \mathrm{T}$ & $\mathrm{N} / \mathrm{T}$ & $\mathrm{N} / \mathrm{T}$ & $\mathrm{N} / \mathrm{T}$ & 0 & $1(1 \%)$ & - & - \\
\hline Shigella spp. & $\mathrm{N} / \mathrm{T}$ & $\mathrm{N} / \mathrm{T}$ & $\mathrm{N} / \mathrm{T}$ & $\mathrm{N} / \mathrm{T}$ & 0 & $10(10 \%)$ & - & - \\
\hline Serratia species & $\mathrm{N} / \mathrm{T}$ & $\mathrm{N} / \mathrm{T}$ & $\mathrm{N} / \mathrm{T}$ & $\mathrm{N} / \mathrm{T}$ & 0 & $6(6 \%)$ & - & - \\
\hline E.aerogenes & $\mathrm{N} / \mathrm{T}$ & $\mathrm{N} / \mathrm{T}$ & $\mathrm{N} / \mathrm{T}$ & $\mathrm{N} / \mathrm{T}$ & 0 & $1(1 \%)$ & - & \\
\hline Total & 106 & 184 & 66 & 40 & 4 & 101 & 4 & \\
\hline
\end{tabular}

$\mathrm{N} / \mathrm{T}=$ Not tested

\section{Discussion}

Even if the human GI tract contains full of commensal, they may act as a reservoir for pathogens and may translocate in to sterile site through genetic elements (plasmids). As a result it may increase the resistance pattern. So conducting a research on commensal is very crucial for identifying the resistance strains. In the current study from the total 384 study participants, 404 Enterobacteriaceae were isolated. Among these, E.coli accounts the highest 219(54\%) followed by K.pneumoniae 50(12\%), K. ozenae 15(3.7\%) and Citrobacter 14(3.5\%).The result was lower than a study conducted in Addis abeba, Ethiopia which shows E. coli (79.7\%) was the highest followed by k.pneumoniae (19.7\%) (13); in Libya E.coli (55\%), K.pneumoniae (28.8\%) (25); United Arab Emirates E.coli (63.8\%), K.pneumoniae (34.6\%) (26). This difference may be due to the technique that we used, sample size, geographical distribusion and the study population.

In the present study, the overall prevalence of ESBL was 66/404(16.3\%) which is concordant with a report in France (17.7\%) (27). However, it was lower than a report in Tikur Anbesa Specialized Hospital, Addis Abeba (52\%) (13), Madagaskar 49\% (28), Egypt (65\%) (12), Mozambic University (20\%) (18), Guinea-Bissau (32.6\%) (29), Morocco (42.8\%) (30), Tanzania (34.3\%) (31), Beirut (24.5\%) (32), Southeast Asia (50.7\%) (6), Venezuela (34.6\%) (33), Turkey (30\%) (34), Sweeden 35\% (35), Korea (28\%) (36) and Argentina 18.9\% (37). This variation may be due to the diferrence in diagnostic method, study population and geographical location. In contrast, the current finding was higher than a study conducted in Libiya (13.4\%) (25), Japan 6.2\% (38), Amsterdam (8.6\%) (10), France 4.6\% (39), Soudi Arabia 91(12\%) (40), Netherland 73(10\%) (41), Norway 15.8\% (11), Swetherland (5.8\%) (42). This variation may be due to the antibiotic practice used in the population, geographical location, and poor personal and environmental hygienic practices.

Our finding showed that 41/66 (62\%) E.coli were ESBL positive which is inline with a report in Mozambic University (62\%) (18). But lower than a study done in Tikur Ambesa Specialized Hospital, Addis Abeba (70\%) (13), Norway (86\%) (11), Saudi Arabia (95.6\%) (37), France (89\%) (39), Japan (78.5\%) (38), Southeast Asia (97\%) (6). However, it 
was higher than a study conducted in Madakascar 32\% (28), Guinea-Bissau (47\%) (29), Morocco 48.5\% (30), New York (60\%) (26). This discrepancy of isolation may be due to geographical location, poor hygienic practice, irrational use of antibiotics, and study populations.

In this study, the over all prevalence of CPE was 4/404(1\%), but the finding is not concordant with other studies. As a result, the present study is lower than a study conducted in Tikur Ambesa Specialized Hospital, Addis Abebea (2\%) (13), Egypt (2\%) (43), Morocco (13\%) (30), Uganda 10\% (44), India (6.6\%) (45), Mexico (16.6\%) (46). However, our study reported higher prevalence than a study done in Mozambic (0.8\%) (18), Norway (0\%) (11), Korea (0.3\%) (36), Asia $0.6 \%$ (47). This discrepancy of isolation may be due to geographical location, poor hygienic practice, inappropriate use of antibiotics, cross boarder of patients with other countries of high prevalence, sample size, methodological variability could bring variation in the prevalence of CPE.

In this study, the overall prevalence of MDR-Enterobacteriaceae (MDR-E) was 196(48.5\%) which is similar with a study done in Norway 48\% (11). However, our result is lower than a study done in Mozambic University $88 \%$ (18) and Switherland 51\% (42). But it was higher than a study conducted in Tikur Ambesa Specialized Hospital Addis Abeba 43\% (13), Madagaskar 41.9\% (28), Morocco 42.8\% (30), India 12.4\% (45). This discrepancy may be due to irrational use of antibiotic, poor personal and environmental hygienic practis in the study area and also scarcity of proper diagnostic tools and also it may be consumption of animal product that takes antibiotics for growth promotion and teatment purpose, increased trend of MDR strains with time, differences in study population, failure of patient adherence to their medication, and unavailability of guidelines for the selection of antibiotics.

\section{Limitation of the study}

This study was conducted in the hospital setting in a small sample size. This study also did not include other important pathogens responsible for gastro intersinal complain due to lack of laboratory facility.

\section{Conclusion}

Multi drug resistant, extended spectrum beta lactamase and carbapenemase producing Enterobacteriaceae were higher in the gastrointestinal tract infections. E.coli was the most predominant ESBL-PE followed by K.pneumoniae.

Finding high rate of drug resistance in Gram-negative bacteria require strict infection control measures and careful selection of empirical therapy in the study area. Even if many Enterobacteriaceae are human fecal normal flora, they carry resistance gene and act as a reservoir. If MDR-Enterobacteriaceae is isolated ESBL and CPE should be screened to improve the infection prevention practice. Active surveillance with large sample size will also be performed to know the high prevalence of ESBL and CPE in gastrointestinal tract infections.

\section{List Of Abbreviations}

ATCC: American Type Culture Collection; AMR: Anti Microbial Resistance; CLSI: Clinical and Laboratory Standard Institute; CPE: Carbapenemase Producing Enterobacteriaceae; CRE: Carbapenem Resistance Enterobacteriaceae; ESBL: Extended Spectrum Beta-Lactamase; ESBL-PE: Extended Spectrum Beta-Lactamase-Producing Enterobacteriaceae; GIT: Gastro-Intestinal Tract; ICU: Intensive Care Unit; mCIM: Modified Carbapenem Inactivation Method; MDR: ulti Drug Resistance; OPD: Out Patient Department; QC: Quality control. 


\section{Declarations}

\section{Acknowledgements}

The authors are pleased to acknowledge the study participants who accepted to participate in this study as well as Department of Medical Microbiology for their support by giving different materials and Medical Microbiology laboratory assistant for their technical support. Antibiotic disks for extended spectrum beta lactamase detection were also supported by Ethiopian public health institute staff.

\section{Funding}

Not applicable

\section{Availability of data and materials}

The datasets used and/or analyzed during the current study available from the corresponding author on reasonable request.

\section{Authors' contributions}

MW collected the data.MW and AG wrote the manuscript. AG, FM and MG gave valuable suggestions of the manuscript and revised the manuscript. All authors read and approved the final version of the manuscript.

\section{Ethics approval and consent to participate}

The study was conducted after obtaining ethical clearance from ethical review committee of the School of Biomedical and Laboratory Sciences, College of Medicine and Health Sciences University of Gondar. Legal permission letter was also obtained from hospital clinical directors prior to data collection. Only those who were volunter to participate in the study was asked to give samples and soco-demomgrapic data. Written Consent was obtained from study participnts and guardians. In addition to consent from the guardians, an assent was also asked from under 18 years old patients. Information obtained from each participants was kept confidential.

\section{Consent for publication}

Not applicable

\section{Cempeting interests}

The authors declare that they have no competing interests.

\section{References}

1. Kocsis B, Szabó D. Antibiotic resistance mechanisms in Enterobacteriaceae. Microbial pathogens and strategies for combating them: Science, Technology and EducationSemmelweis University. 2013;1.

2. Levinson W. Review of Medical Microbiology and Immunology. University of California: McGraw-Hill Education; 2014. 1950.

3. Mittal G, Gaind R, Kumar D, Kaushik G, Gupta KB, Verma PK, et al. Risk factors for fecal carriage of carbapenemase producing Enterobacteriaceae among intensive care unit patients from a tertiary care center in India. BMC Microbiology. 2016;16:138. 
4. Rai S, Das, D, Niranjan, DK., Singh NP, Kaur IR. Carriage prevalence of carbapenem-resistant Enterobacteriaceae in stool samples: A surveillance study. The Australasian Medical Journal. 2014;7(2):64-7.

5. Hazirolan G, Mumcuoglu I, Altan G, zmen B, Aksu N, et al. Fecal carriage of extended-spectrum beta-lactamase and ampc beta-lactamase-producing enterobacteriaceae in a turkish community. Nigerian Journal of Clinical Practice. 2018;21(1):81-6.

6. Barreto Miranda I, Ignatius R, Pfüller R, Friedrich-Jänicke B, Steiner F, Paland M, et al. High carriage rate of ESBLproducing Enterobacteriaceae at presentation and follow-up among travellers with gastrointestinal complaints returning from India and Southeast Asia. Journal of Travel Medicine. 2016;23(2):024.

7. Toubiana J, Timsit S, Ferroni A, Grasseau M, Nassif X, Lortholary O, et al. Community-onset Extended-spectrum $\beta$-lactamase-producing enterobacteriaceae Invasive Infections in Children in a University Hospital in France. Medicine. 2016;95(12).

8. Woerther PL, Burdet C, Chachaty E, Andremont A. Trends in human fecal carriage of extended-spectrum $\beta$ lactamases in the community: toward the globalization of CTX-M. Clinical Microbiology Reviews. 2013;26(4):744-58.

9. Legese MH, Weldearegay GM, Asrat Daniel. Extended-spectrum beta-lactamase-and carbapenemase-producing Enterobacteriaceae among Ethiopian children. Infection and Drug Resistance. 2017;10:27.

10. Reuland E, Al Naiemi N, Kaiser A, Heck M, Kluytmans J, Savelkoul P, et al. Prevalence and risk factors for carriage of ESBL-producing Enterobacteriaceae in Amsterdam. Journal of Antimicrobial Chemotherapy. 2016;71(4):1076-82.

11. Jørgensen SB, Samuelsen $\emptyset$, Sundsfjord A, Bhatti SA, Jørgensen I, Sivapathasundaram T, et al. High prevalence of faecal carriage of ESBL-producing Enterobacteriaceae in Norwegian patients with gastroenteritis. Scandinavian Journal of Infectious Diseases. 2014;46(6):462-5.

12. Abdallah H, Alnaiemi N, Reuland E, Wintermans B, Koek A, Abdelwahab A, et al. Fecal carriage of extendedspectrum $\beta$-lactamase-and carbapenemase-producing Enterobacteriaceae in Egyptian patients with communityonset gastrointestinal complaints: a hospital-based cross-sectional study. Antimicrobial Resistance and Infection Control. 2017;6(1):62.

13. Desta K, Woldeamanuel Y, Azazh A, Mohammod H, Desalegn D, Shimelis D, et al. High gastrointestinal colonization rate with extended-spectrum $\beta$-lactamase-producing Enterobacteriaceae in hospitalized patients: emergence of carbapenemase-producing K. pneumoniae in Ethiopia. PloS one. 2016;11(8): 0161685.

14. Ríos E LM, Rodríguez-Avial I, Culebras E, Picazo JJ. Detection of Escherichia coli ST131 clonal complex (ST705) and Klebsiella pneumoniae ST15 among faecal carriage of extended-spectrum $\beta$-lactamase-and carbapenemase-producing Enterobacteriaceae. Journal of Medical Microbiology. 2017;66(2):169-74.

15. Pana ZD ZT. Treatment of extended-spectrum $\beta$-lactamase-producing Enterobacteriaceae (ESBLs) infections: what have we learned until now? F1000Research. 2018;7.

16. Eshetie S, Unakal C, Gelaw A, Ayelign B, Endris M, Moges F. Multidrug resistant and carbapenemase producing Enterobacteriaceae among patients with urinary tract infection at referral Hospital, Northwest Ethiopia. Antimicrobial Resistance and Infection Control. 2015;4(1):12.

17. Seid J, Asrat D. Occurrence of extended spectrum $\beta$-lactamase enzymes in clinical isolates of Klebsiella species from Harar region, eastern Ethiopia. Acta Tropica. 2005;95(2):143-8.

18. Chirindze LM, Zimba TF, Sekyere JO, Govinden U, Chenia HY, Sundsfjord A, et al. Faecal colonization of E. coli and Klebsiella spp. producing extended-spectrum beta-lactamases and plasmid-mediated AmpC in Mozambican university students. BMC Infectious Diseases. 2018;18(1):244. 
19. Gebre-Sealsssie S. Antimicrobial resistance patterns of clinical bacterial isolates in southwestern Ethiopia. Ethiopian Medical Journal. 2007;45(4):363-70.

20. Desta K, Woldeamanuel Y, Azazh A, Mohammod H, Desalegn D, Shimelis D, et al. High gastrointestinal colonization rate with extended-spectrum $\beta$-lactamase-producing Enterobacteriaceae in hospitalized patients: emergence of carbapenemase-producing K. pneumoniae in Ethiopia. PloS one. 2016;11(8):e0161685.

21. Cheesbrough M. District laboratory practice in tropical countries. $2^{\text {nd }}$ edition ed. New York: Cambridge University Press; 2006.

22. CLSI. Performance standard for antimicrobial susceptibility testing. M100. 2019.(29th edition).

23. Kocsis B, Szabó D. Antibiotic resistance mechanisms in Enterobacteriaceae. Microbial pathogens and strategies for combating them: Science, Technology and Education. 2013;1.

24. Dantas CL, Belous LA, Matos MB, Figueira da Costa TN. Prevalence of gastrointestinal complaints during national triathlon competition. RBNE-REVISTA BRASILEIRA DE NUTRICAO ESPORTIVA. 2017;11(64):477-84.

25. Ahmed SF, Ali MMM, Mohamed ZK, Moussa TA, Klena JD. Fecal carriage of extended-spectrum $\beta$-lactamases and AmpC-producing Escherichia coli in a Libyan community. Annals of Clinical Microbiology and Antimicrobials. 2014;13(1):22.

26. Al-Zarouni M, Senok A, Rashid F, Al-Jesmi SM, Panigrahi D. Prevalence and Antimicrobial Susceptibility Pattern of Extended-Spectrum Beta-Lactamase-Producing Enterobacteriaceae in the United Arab Emirates. Medical Principles and Practice. 2008;17(1):32-6.

27. Pilmis B, Cattoir V, Lecointe D, Limelette A, Grall I, Mizrahi A, et al. Carriage of ESBL-producing Enterobacteriaceae in French hospitals: the PORTABLSE study. Journal of Hospital Infection. 2018;98(3):247-52.

28. Andriatahina T, Randrianirina F, Hariniana ER, Talarmin A, Raobijaona H, Buisson $\mathrm{Y}$, et al. High prevalence of fecal carriage of extended-spectrum $\beta$-lactamase-producing Escherichia coli and Klebsiella pneumoniae in a pediatric unit in Madagascar. BMC Infectious Diseases. 2010;10(1):204.

29. Isendahl J, Turlej-Rogacka A, Manjuba C, Rodrigues A, Giske CG, Nauclér P. Fecal carriage of ESBL-producing E. coli and K. pneumoniae in children in Guinea-Bissau: a hospital-based cross-sectional study. PLoS One. 2012;7(12):e51981.

30. Girlich D, Bouihat N, Poirel L, Benouda A, Nordmann P. High rate of faecal carriage of extended-spectrum $\beta$ lactamase and OXA-48 carbapenemase-producing Enterobacteriaceae at a university hospital in Morocco. Clinical Microbiology and Infection. 2014;20(4):350-4.

31. Tellevik MG, Blomberg B, Kommedal Ø, Maselle SY, Langeland N, Moyo SJ. High prevalence of faecal carriage of ESBL-producing Enterobacteriaceae among children in Dar es Salaam, Tanzania. PloS one. 2016;11(12):e0168024.

32. Hijazi S, Fawzi M, Ali F, El Galil KA. Prevalence and characterization of extended-spectrum beta-lactamases producing Enterobacteriaceae in healthy children and associated risk factors. Annals of Clinical Microbiology and Antimicrobials. 2016;15(1):3.

33. Araque M, Labrador I. Prevalence of Fecal Carriage of CTX-M-15 Beta-Lactamase-Producing Escherichia coli in Healthy Children from a Rural Andean Village in Venezuela. Osong public health and research perspectives. 2018;9(1):9.

34. ERDOĞAN DÇ, CÖMERT F, SEPETCI EA, KÖKTÜRK F, KÜLAH C. Fecal carriage of extended-spectrum betalactamase-producing Escherichia coli and Klebsiella spp. in a Turkish community. Turkish Journal of Medical Sciences. 2017;47(1):172-9. 
35. Angelin $\mathrm{M}$, Forsell J, Granlund $\mathrm{M}$, Evengård $\mathrm{B}$, Palmgren $\mathrm{H}$, Johansson $\mathrm{A}$. Risk factors for colonization with extended-spectrum beta-lactamase producing Enterobacteriaceae in healthcare students on clinical assignment abroad: A prospective study. Travel Medicine and Infectious Disease. 2015;13(3):223-9.

36. Kim J, Lee JY, Kim SI, Song W, Kim J-S, Jung S, et al. Rates of fecal transmission of extended-spectrum $\beta$ lactamase-producing and carbapenem-resistant Enterobacteriaceae among patients in intensive care units in Korea. Annals of Laboratory Medicine. 2014;34(1):20-5.

37. Villar HE, Baserni MN, Jugo MB. Faecal carriage of ESBL-producing Enterobacteriaceae and carbapenemresistant Gram-negative bacilli in community settings. The Journal of Infection in Developing Countries. 2013;7(08):630-4.

38. Luvsansharav UO, Hirai I, Niki M, Nakata A, Yoshinaga A, Yamamoto Y, et al. Prevalence of fecal carriage of extended-spectrum $\beta$-lactamase-producing Enterobacteriaceae among healthy adult people in Japan. Journal of Infection and Chemotherapy. 2011;17(5):722-5.

39. Birgy A, Cohen R, Levy C, Bidet P, Courroux C, Benani M, et al. Community faecal carriage of extended-spectrum beta-lactamase-producing Enterobacteriaceae in French children. BMC Infectious Diseases. 2012;12(1):315.

40. Kader AA, Kamath KA. Faecal carriage of extended-spectrum beta-lactamase-producing bacteria in the community. EMHJ. 2009;15(6):1365-70.

41. Reuland E, Overdevest I, Al Naiemi N, Kalpoe J, Rijnsburger M, Raadsen S, et al. High prevalence of ESBLproducing Enterobacteriaceae carriage in Dutch community patients with gastrointestinal complaints. Clinical Microbiology and Infection. 2013;19(6):542-9.

42. Nüesch-Inderbinen MT, Abgottspon H, Zurfluh K, Nüesch HJ, Stephan R, Hächler H. Cross-sectional study on fecal carriage of Enterobacteriaceae with resistance to extended-spectrum cephalosporins in primary care patients. Microbial Drug Resistance. 2013;19(5):362-9.

43. Sayed AM, Behiry IK, Elsherief RH, Elsir SA. Detection of carbapenemase-producing Enterobacteriaceae in rectal surveillance cultures in non-hospitalized patients. Journal of Analytical Science and Technology. 2017;8(1):4.

44. Ampaire LM, Katawera V, Nyehangane D, Boum Y, Bazira J. Epidemiology of carbapenem resistance among multi-drug resistant enterobacteriaceae in Uganda. British Microbiology Research Journal. 2015;8(2):418.

45. Mittal G, Gaind R, Kumar D, Kaushik G, Gupta KB, Verma P, et al. Risk factors for fecal carriage of carbapenemase producing Enterobacteriaceae among intensive care unit patients from a tertiary care center in India. BMC Microbiology. 2016;16(1):138.

46. Torres-Gonzalez P, Cervera-Hernandez ME, Niembro-Ortega MD, Leal-Vega F, Cruz-Hervert LP, García-García L, et al. Factors associated to prevalence and incidence of carbapenem-resistant Enterobacteriaceae fecal carriage: a cohort study in a Mexican tertiary care hospital. PLoS One. 2015;10(10):0139883.

47. Xu Y, Gu B, Huang M, Liu H, Xu T, Xia W, et al. Epidemiology of carbapenem resistant Enterobacteriaceae (CRE) during 2000-2012 in Asia. Journal of Thoracic Disease. 2015;7(3):376.

\section{Figures}




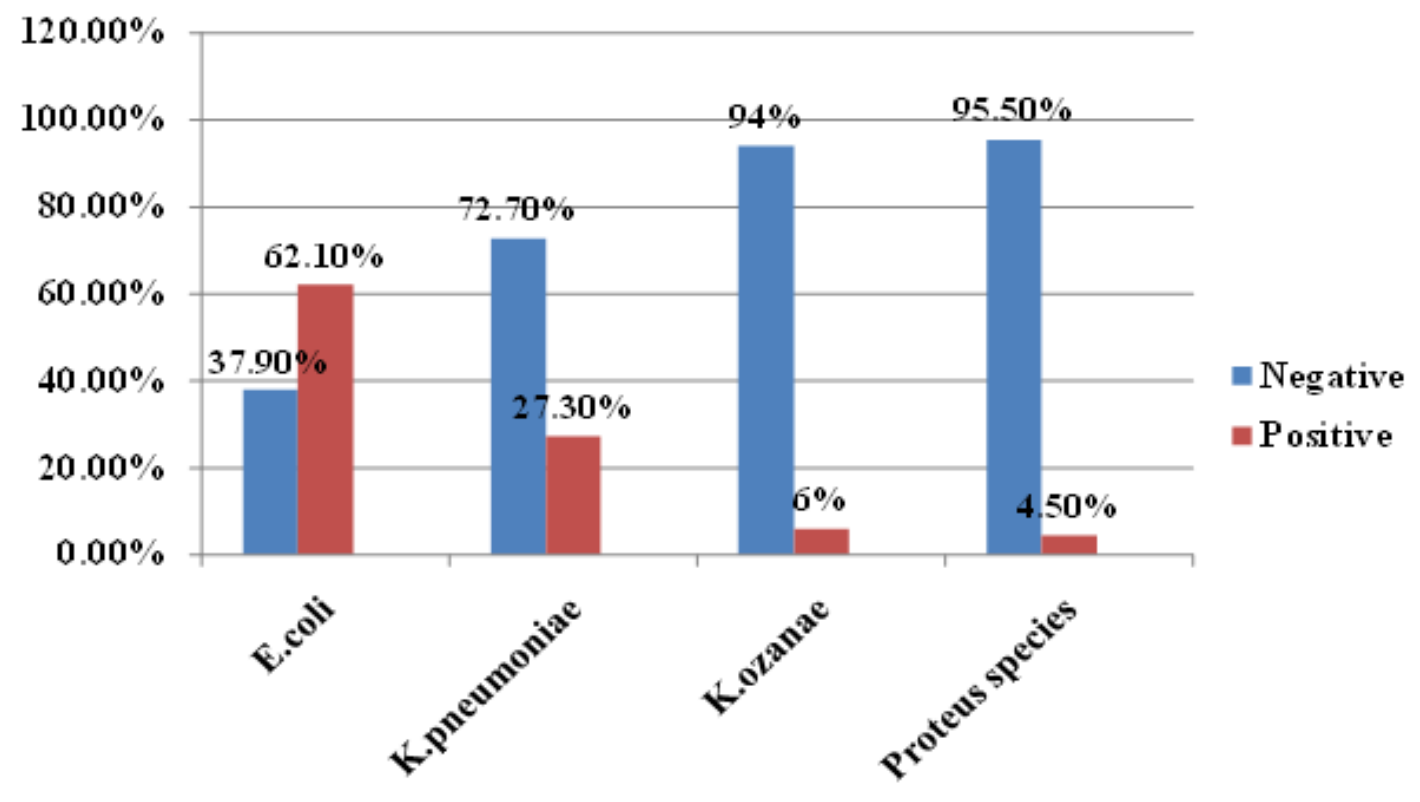

Figure 1

Distribution of ESBL-PE from Patients with Gastrointestinal Complaints at the University of Gondar Comprehensive Specialized Hospital from January - June, 2019 